Rapp. Grønlands geol. Unders. 79, 27-33 (1977)

\title{
CORAL-BEARING MATERIAL ASSOCIATED WITH A THOLEIITIC DYKE IN THE SORDLÛT VALLEY, NÛGSSUAQ
}

\author{
E. J. Schiener and S. Floris
}

Three coral-bearing samples (GGU 176128, A, B \& C) from a Lower Tertiary tholeiitic dyke were collected by Henderson (this report) from the Sordlût valley. S. Floris determined and commented on the fossil content; E. J. Schiener evaluated the petrography.

\section{Sample preparation}

Samples were cut and the resulting faces were ground with 400 mesh abrasive. After short etching with $\mathrm{n} / 8 \mathrm{HC} 1$ the ground faces were stained with Alizarin red $\mathrm{S}$ and potassium ferricyanide, modified after Dickson (1965). Acetate peels were prepared after the staining.

\section{Sample description}

Of the three samples supplied A and C proved to be identical in lithology, whereas $B$ differed in several aspects of matrix composition, the presence of basalt clasts in the framework and in the fabric of the carbonate framework.

\section{Matrix}

In samples $\mathrm{A} \& \mathrm{C}$ the finest part of the matrix consists of very finely comminuted $(<0.01 \mathrm{~mm})$ hyaloclastite material of basaltic provenance. The blue-green staining indicates the presence of microcrystalline ferroan calcite in the heavily devitrified (palagonitized) matrix (Nayudu, 1964).

The matrix of sample $176128 \mathrm{~B}$ consists exclusively of glassy material, although with considerably smaller size range $(0.01 \mathrm{~mm}-$ submicroscopic). This fine part of the matrix supports larger components $(0.25-3.0 \mathrm{~mm}$ diameter $)$ of predominantly igneous origin. They are, owing to their similarity in composition, considered to have originated through the same igneous processes and thus to constitute an essential part of the matrix. Particles are only rarely in grain-grain contact.

The coarser part of the matrix in samples $\mathrm{A}$ and $\mathrm{C}$ comprises two varieties of igneous material. The most abundant consists of fragments with irregular, frayed outlines; maximum diameters are around $3 \mathrm{~mm}$, with an average around $1.0 \mathrm{~mm}$. The greyish reflecting, 


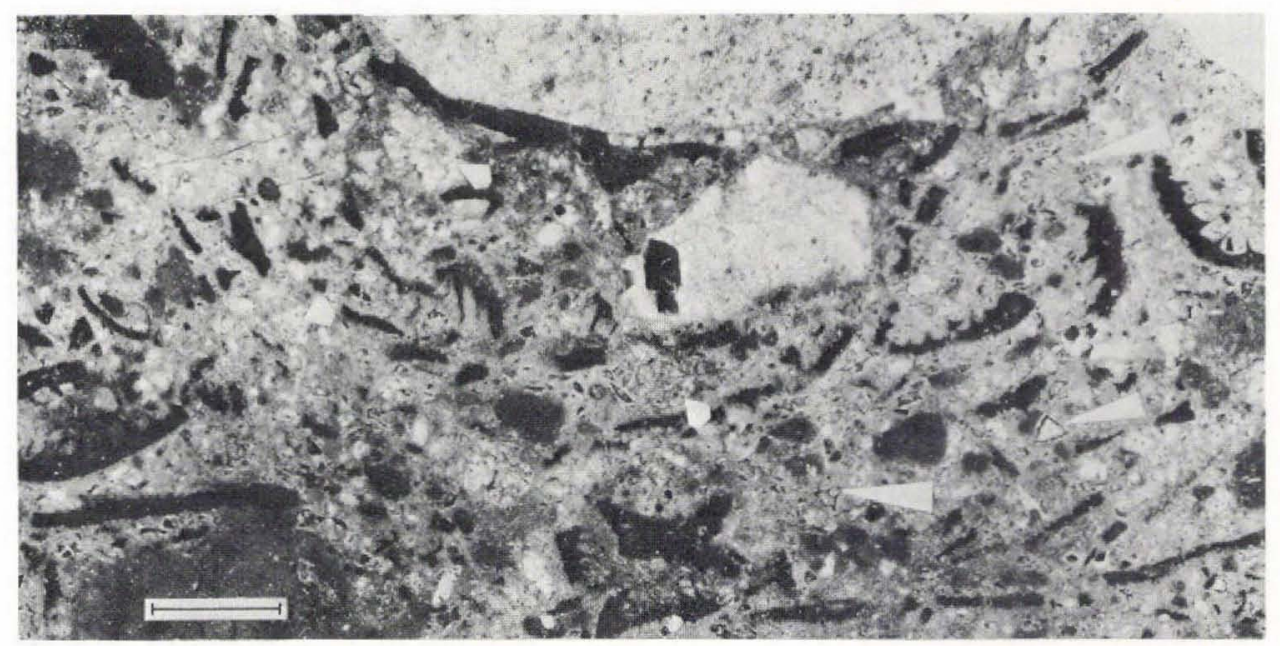

Fig. 13. Detail of matrix composition and framework relationships. Slender arrows: angular, glassy hyaloclastites, blunt arrows: irregular, devitrified hyaloclastites. GGU $176128 \mathrm{~A}$, stained slab. Scale $2 \mathrm{~mm}$.

glassy groundmass contains both minute crystallites and occasionally large single crystals of sparry, dark brown ankerite. Irregular cooling cracks are filled by turquoise stained microcrystalline ferroan dolomite, that also is observed as haloes around patchy pyrite (fig. 13).

The second fraction is represented by sharp angled fragments occasionally containing vesicles and commonly displaying palagonitized rims. The longest diameters range between 0.25 and $0.5 \mathrm{~mm}$. Staining did not affect these components (fig. 13).

Also considered with the bulk of the matrix are discrete pellets, on average $0.5 \mathrm{~mm}$ across, but reaching maximum diameters of $12 \mathrm{~mm}$. The small pellets generally have circular cross sections. Larger pellets are either flattened or drawn out into irregular lumps. They consist of the very fine hyaloclastite matrix material.

\section{Framework}

The framework components are almost exclusively matrix supported. In samples 176128 A \& C they consist predominantly of scleractinian coral debris. In sample $176128 \mathrm{~B}$ microcrystalline and glassy basalt occurs in addition to the coral fragments. Some of the basalt pieces and a few corals are encrusted by serpulids. A few tests of foraminifera and remains of echinoderms, bivalves and gastropods are also present, together with one fish vertebra.

\section{Framework fabric}

There are differences in the spatial arrangement of coral derived framework particles between samples $176128 \mathrm{~A} \& \mathrm{C}$ and $176128 \mathrm{~B}$. 
Fig, 14. Coarse hyaloclastite matrix with subparallel aligned coral fragments. Void space in corallites filled with sparry ankerite.

GGU $176128 \mathrm{C}$, stained slab. Scale

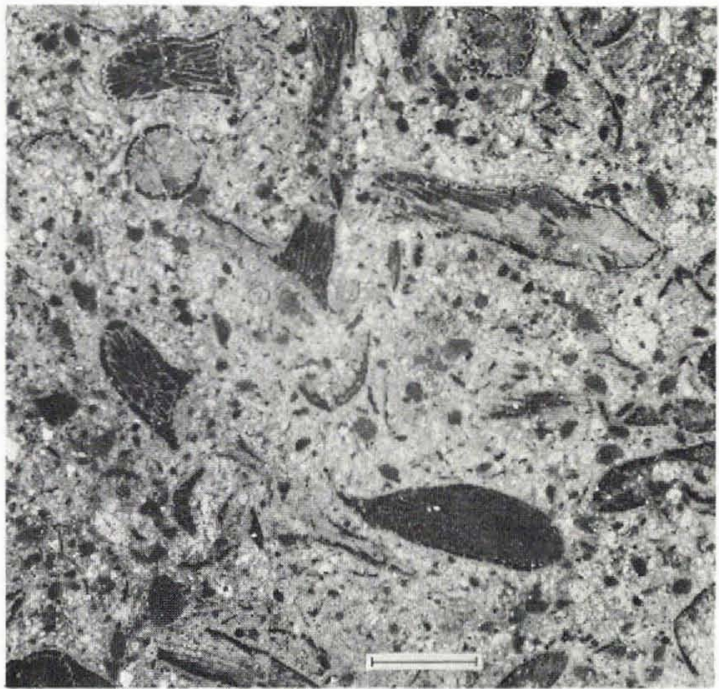
$4 \mathrm{~mm}$.

In $\mathrm{A} \& \mathrm{C}$ the majority of corallite fragments are structurally well preserved. The longest longitudinal sections exceed $15 \mathrm{~mm}$. Only in a few cases can compactional rupturing or more thorough damage of walls and septa be seen (fig. 14). The corallite fragments show some degree of preferential orientation: in the plane of section either circular cross sections or parallel aligned longitudinal sections occur. In the few marginal positions, where basalt fragments are in contact with the coral framework, realignment of the coral debris to accommodate to the shape of the basalt fragment is observable.

In $\mathrm{B}$ the majority of corallite fragments are small, rarely exceeding $5 \mathrm{~mm}$ in longitudinal section. Walls and septa are frequently disrupted to give rise to small platy carbonate particles (fig. 15).

Accumulations of this coral debris form irregular 'schlieren' in central parts of the sectioned specimen. Towards the margin, where the basalt components are also in contact with the carbonate framework, very pronounced accomodation of the latter to the rather irregularly shaped basaltic fragments can be seen. The accommodation is for instance seen in relation to serpulid-encrusted surfaces of basalt fragments.

\section{Basalt fragments}

Basalt fragments that owing to their large size are included in the framework are observable only in marginal parts of the specimens investigated. Most of the observations described below are based on examination of sample 176128 B. Two basalt varieties can be distinguished, a dense, glassy basalt with only a few feldspar laths and a fine grained basalt with abundant microscopic laths. Some of the relatively large pieces of basalt in sample $176128 \mathrm{~B}$ are broken and the interstitial spaces filled with matrix material.

In some cases it can be observed that the glassy variety forms the chilled margins of micropillows of the fine grained basalt (fig. 16). Frequently these chilled margins have 


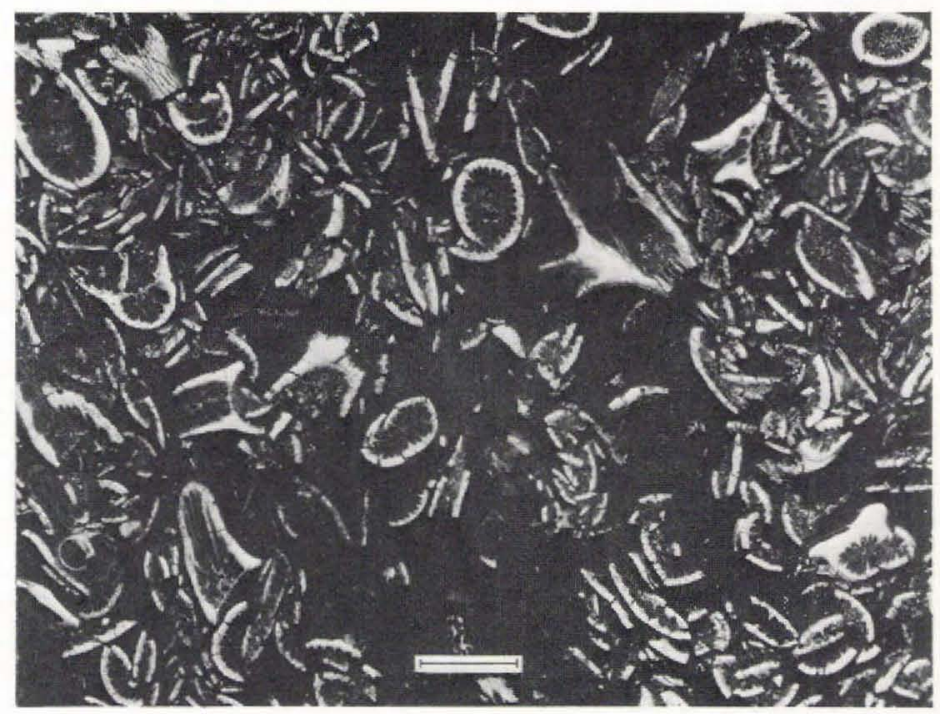

Fig. 15.

Submicroscopic hyaloclastite matrix with 'Schlieren' arrangement of coral fragments. GGU $176128 \mathrm{~B}$, stained slab. Scale $4 \mathrm{~mm}$.

spalled off and given rise to angular glassy pieces, where the original curved outline is preserved. Irregularly frayed glassy fragments also occur; their relations are less clearly established, but since they are seen to surround coral fragments, they probably originated in the same environment.

\section{Diagenetic features of framework carbonates}

The difference in composition of the matrix between the samples mentioned above is reflected in the diagenetic changes of the framework carbonate. In samples $176128 \mathrm{~A} \& \mathrm{C}$ recrystallization to magnesian calcite microspar has affected skeletal parts of the corallites, whereas voids are either filled with sparry ankerite or, less commonly, permeated by matrix. In exceptional cases the corallite tube is loosely filled with glassy angular matrix components and subsequently cemented by sparry ankerite. The interior of the corallite parts crushed in situ is filled with fine matrix or ankerite.

In sample $176128 \mathrm{~B}$ corrallites and derived fragments are hardly affected by recrystallization to magnesian calcite. The fibrous trabeculae of the corallites are still recognizable. Pink and red staining indicates that the skeletons are calcitic.

Since almost all void space is permeated by the fine primary matrix in this case, sparry calcite cement is developed only to a small extent.

\section{Determination of the coral material}

The scleractinian coral remains dominate in the three samples investigated. They consist of broken and crushed fragments of slender branches with in places well preserved details of walls and septal arrangement. Budding is commonly observed but calices and bases have not been demonstrated. Serpulids have encrusted a few of the branches. The coral 
Fig. 16. 'Micropillow' of basalt with spalled glassy margins in very fine grained hyaloclastite matrix. Coral fragments strongly comminuted. GGU 176128 B, stained slab. Scale $2 \mathrm{~mm}$.

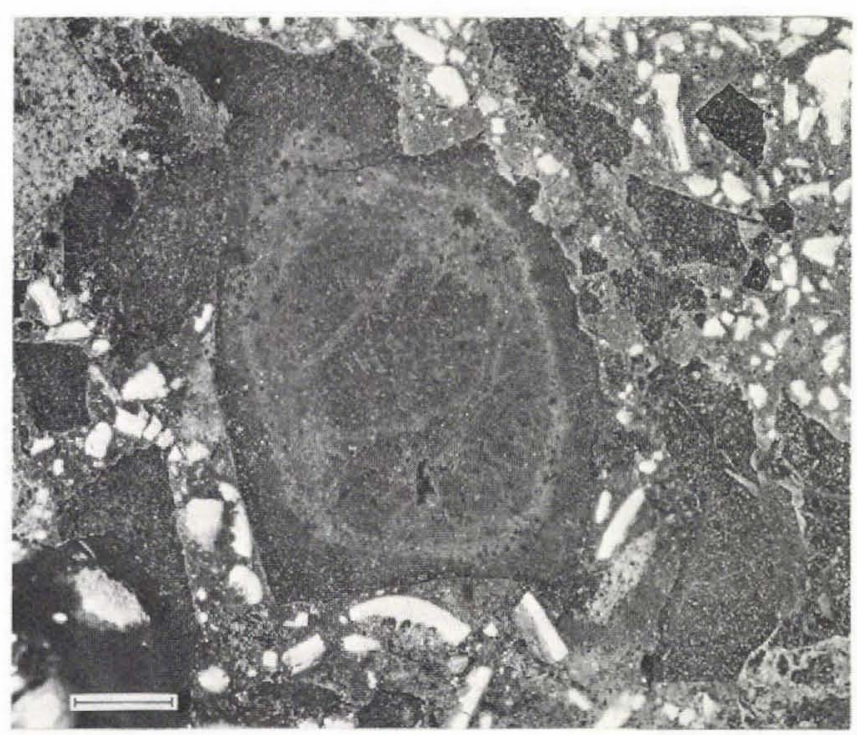

material closely resembles forms from Greenland basalt tuff of Lower Danian (and also of probable Lower Danian) age, which were analyzed in detail by Floris (1972), who referred them to the European Danian (and Heersian?) species, Dendrophyllia candelabrum Hennig, 1899. The corals are therefore determined as members of this variable species. (Jürgensen \& Mikkelsen, 1974, suggested that at least one of the Greenland occurrences with $D$. candelabrum could be considered of Upper Danian age.)

The abundance in the present samples of fragments buried unworn or not much worn and with many of them empty indicates that they result from a sudden destruction of more than one colony growing in the near vicinity. The species is known to have been a gregarious ahermatypic coral, and probably the destroyed colonies have formed a monotypic thicket (Squires, 1964).

The substrate of the living corals is not known with certainty, but since serpulids encrust both corals and basalt pieces, it is possible that basaltic rubble formed the substrate.

The species is believed to have lived at depths of about $50-80 \mathrm{~m}$ (Floris, 1972).

\section{Interpretation}

The lack of detailed information on field relationships restricts the interpretative part to conclusions that can be drawn from observations on the samples supplied. Even with this limitation valuable facets of the depositional environment and of sedimentation processes in this structurally very interesting part of Nûgssuaq can be obtained. 


\section{History and environment of deposition}

The fine, nearly submicroscopic part of the hyaloclastite matrix in samples $\mathrm{A}$ and $\mathrm{C}$ and the entire matrix of sample B represent the 'indigenous' sediment of the environment.

This matrix material has presumably accumulated as hyaloclastite (Carlisle, 1963) mud representing the finest outwash from the pillow breccias. The size range of the hyaloclastite matrix, the absence of epiclastic material and the presence of hyaline foraminifera indicate a marine environment sufficiently protected or remote from a shore zone to prevent sedimentation other than from suspension. The water depth can only be speculated on, but the existence in the close vicinity of the outcrop of single foresets in the pillow breccias covering at least $150 \mathrm{~m}$ difference in altitude can be taken as an indication. It can also be inferred from these foresets that there were considerable differences in relief. The supposed faecal pellets consisting of fine matrix presumably belong to this indigenous sediment.

The coarser part of the matrix in samples $\mathrm{A}$ and $\mathrm{C}$ shows signs of having been introduced into the depositional environment of the fine hyaloclastites. Its inhomogeneity, the indications of layering and the content of faecal pellets are the main arguments for this interpretation. The matrix supports partly fragmented remains of benthic organisms some of which are filled with hyaloclastite sediment. The coarse components with their frayed outlines appear to have formed by subaqueous explosive disruption of lava (Fiske \& Matsuda, 1964). Settling from the subaqueous ash-cloud with subsequent formation of gravity induced slurry flows could be the mechanisms involved in the distribution of this matrix component. Of the framework components all of the coral fragments show signs of dislocation of differing extent. Transport is indicated to have been only of short duration and over a short distance. Based on the above comments on the corals, it can be suggested that the biotope was a basalt pebble area at a relatively shallow depth.

The one author (E. J. Schiener) considers that combining the observations on the 'schlieren' fabric of the coral fragments and their contact with the basalt components it is probable that the basaltic magma was intruded into plastic, wet sediment, a conclusion that is in agreement with the field evidence.

The other author (S. Floris) thinks that the samples represent a heterogenous sediment from a mud flow which was triggered off at the same time as the dyke was emplaced, and that the mud flow material filled the interstices in the upper part of the cooling dyke.

\section{Conclusions}

(1) Rocks rich in calcareous fossils are a rather rare occurrence in the CretaceousTertiary sequence of central West Greenland. This outcrop provides another, very unusual, example.

(2) The occurrence shows that at the start of the volcanism there were quiet periods when the environmental conditions permitted the growth of corals.

(3) The material provides one of the few opportunities for dating the lower part of the volcanic sequence by means of fossils.

(4) The combination of field observation and of detailed investigation of sample material provides evidence for contemporaneous subaerial and submarine volcanic activity at the 
beginning of the Early Tertiary volcanism on Nûgssuaq. It substantiates further the locally strong differences in relief, although absolute values for water depths cannot be derived from the data available.

The evolutionary history of the dyke and the associated coralbearing rocks is more complex than first realized. The dyke locality warrants further examination and sampling.

The samples are kept in the Geological Museum, University of Copenhagen, under the numbers MGUH 13 975-13 977, respectively.

\section{References}

Carlisle, D. 1963: Pillow breccias and their aquagene tuffs, Quadra Island, British Columbia. J. Geol. 71, 48-71.

Dickson, J. A. D. 1965: A modified staining technique for carbonates in thin section. Nature 205, 587 only.

Fiske, R. S. \& Matsuda, T. 1964: Submarine equivalents of ash flows in the Tokiwa Formation, Japan. Amer. J. Sci. 262, 76-106.

Floris, S. 1972: Scleractinian corals from the Upper Cretaceous and Lower Tertiary of Nugssuaq, West Greenland. Bull. Grønlands geol. Unders. 100, $132 \mathrm{pp}$.

Jürgensen, T. \& Mikkelsen, N. 1974: Coccoliths from volcanic sediments (Danian) in Nûgssuaq, West Greenland. Meddr dansk geol. Foren. 23, 225-230.

Nayudu, I. R. 1964: Palagonite tuffs (hyaloclastites) and the products of post-eruptive processes. Bull. Volc. 27, 391-410.

Squires, D. F. 1964: Fossil coral thickets in Wairarapa, New Zealand. J. Paleont. 38, 904-915. 